\title{
Analytical Model for the End-Bearing Capacity of Tapered Piles Using Cavity Expansion Theory
}

\author{
Suman Manandhar and Noriyuki Yasufuku \\ Department of Civil Engineering, Kyushu University, 744 Motooka, Fukuoka 819-0395, Japan \\ Correspondence should be addressed to Noriyuki Yasufuku, yasufuku@civil.kyushu-u.ac.jp \\ Received 2 May 2012; Revised 21 September 2012; Accepted 5 October 2012 \\ Academic Editor: John Mander
}

Copyright ( $) 2012$ S. Manandhar and N. Yasufuku. This is an open access article distributed under the Creative Commons Attribution License, which permits unrestricted use, distribution, and reproduction in any medium, provided the original work is properly cited.

On the basis of evidence from model tests on increasing the end-bearing behavior of tapered piles at the load-settlement curve, this paper proposes an analytical spherical cavity expansion theory to evaluate the end-bearing capacity. The angle of tapering is inserted in the proposed model to evaluate the end-bearing capacity. The test results of the proposed model in different types of sands and different relative densities show good effects compared to conventional straight piles. The end-bearing capacity increases with increases in the tapering angle. The paper then propounds a model for prototypes and real-type pile tests which predicts and validates to evaluate the end-bearing capacity.

\section{Introduction}

The pile end-bearing capacity in sands is not only affected by the compressibility of soil, shear stiffness, and strength, but also by the angle of tapering of the pile. Very few researchers have noticed the effects of tapering angle in end-bearing resistance when penetrated downward in a frictional mode [1]. The shape of the pile type changes from a straight-sided cylindrical shape to a conical type, while the weight and volume of the pile appendages to the ground and mechanism also change. Therefore, the tapering effects must be taken into consideration when evaluating the end-bearing capacity of tapered piles [2,3]. There are two main methods to evaluate the end-bearing capacity: a semiempirical method using SPT-N values and a theoretical approach based on geomechanical considerations. Out of all the theoretical methods of geomechanics, the cavity expansion theory is particularly popular among geotech experts [4-6]. Yasufuku et al. derived successfully an evaluation technique for the end-bearing capacity in nondisplacement straight cylindrical piles using a spherical cavity expansion theory for closed solutions $[7,8]$. This research asserts the use of the spherical cavity expansion theory as a way of evaluating the endbearing capacity of tapered piles based on axial cylindrical model tests. The tapering angle is inserted in the analytical model to evaluate the ultimate end-bearing capacity of the spherical cavity expansion theory previously postulated by Yasufuku et al. [7, 8]. The proposed model then referred to predict and validate other prototypes and real-type pile reference data to estimate the end-bearing capacity.

\section{Methodology and Evidence from Test Results}

Chromium-plated three steel piles-one straight $(S)$ and two taper-shaped (T-1 and T-2) -were used for model tests (Table 1) on modeled ground, having relative densities of $60 \%$ and $80 \%$, respectively (Table 2 ). The model piles have equal lengths and the same tip diameters. The model chamber has dimensions of $1000 \mathrm{~mm}$ height and a diameter of $750 \mathrm{~mm}$, as shown by Figure 1(a).

Japanese Industrial System (JIS A 1224) and Japanese Geotechnical Standards (JGS 0161) [9] were used to determine the maximum and minimum dry densities of sands so as to determine the relative densities (Table 2). A multiple sieving technique was used to prepare model ground at an appropriate relative density by height of fall and nozzle diameter. Changes in nozzle area and/or diameter of multiple sievings determine the relative density of the ground when particles fall at a specific height and vice versa [10]. In this 


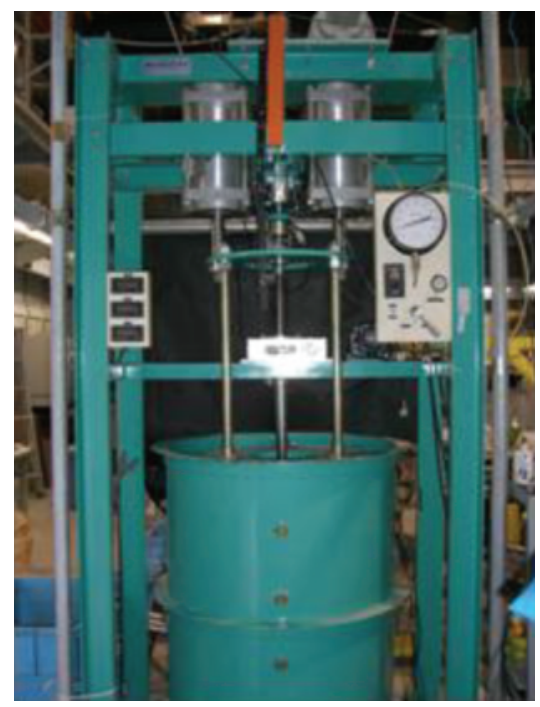

(a)

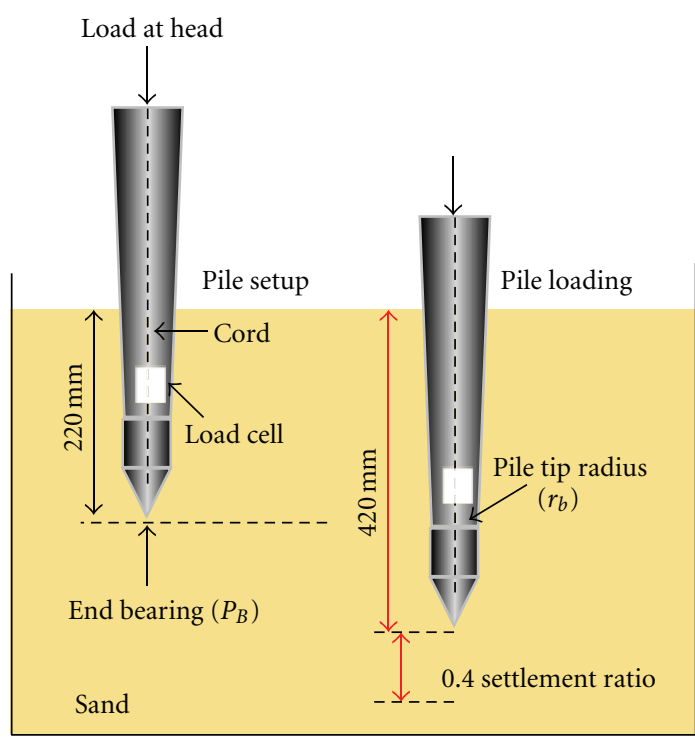

(b)

Figure 1: (a) Pile load chamber and (b) cast-in-place pile set up and loading mechanism (figure not to scale).

method, the height of falling was determined by keeping a constant nozzle area. Then, two sands, K-7 and Toyoura (TO) sands, were allowed to fall through multiple sievings from the heights of $1400 \mathrm{~mm}$ and $700 \mathrm{~mm}$, respectively. The pile was installed at a height of $710 \mathrm{~mm}$ from the bottom, and soil was further poured in up to a height of $930 \mathrm{~mm}$, as shown by Figure 1(b). Following this, an overburden pressure $\left(\sigma_{v}\right)$ of $50 \mathrm{kPa}$ was furnished vertically through the upper plate, and the pile was installed up to $200 \mathrm{~mm}$ at a rate of $5 \mathrm{~mm} / \mathrm{min}$ to facilitate in cast-in-place pile condition. A minimum of fifteen hours is required for stress relaxation after installation. Afterwards, a pile loading test was performed up to 0.4 settlement ratio. In the loading test, load cells were installed inside the pile tip and at the pile head, which were connected with the cord. During loading, the load cell at the pile tip can measure directly the endbearing capacity of the pile.

Figure 2 shows evidence obtained from model test results of straight and tapered piles of K-7 and TO sands. These tests show that when the tapering angle increases, the pile tip resistance increases for both sands at a normalized settlement ratio. Here, $S$ and $D$ are considered as settlement and the pile tip diameter, respectively. The normalized total end-bearing capacity has been plotted by dividing mean effective stress $\sigma^{\prime}$ which is the mean of lateral and vertical stresses (i.e., $\sigma^{\prime}=$ $\left.\left(\sigma_{0}+\sigma_{v}\right) / 2\right)$. For normally consolidated soil, the lateral stress can be determined by selecting a 0.5 -value in the relation between lateral and overburden stresses (i.e., $\sigma_{0}=K_{0} \sigma_{v}^{\prime}$ ), where $K_{0}$ is the coefficient of earth pressure at rest relating with dry unit weight of the ground and its depth. Figure 3 shows the normalized total end-bearing capacity of sands at different relative densities. The result adds tapering effects to the end-bearing mechanism by increasing the tapering angle. This evidence obtained through small model tests explains the merits over tapered piles. Given this, it is necessary to

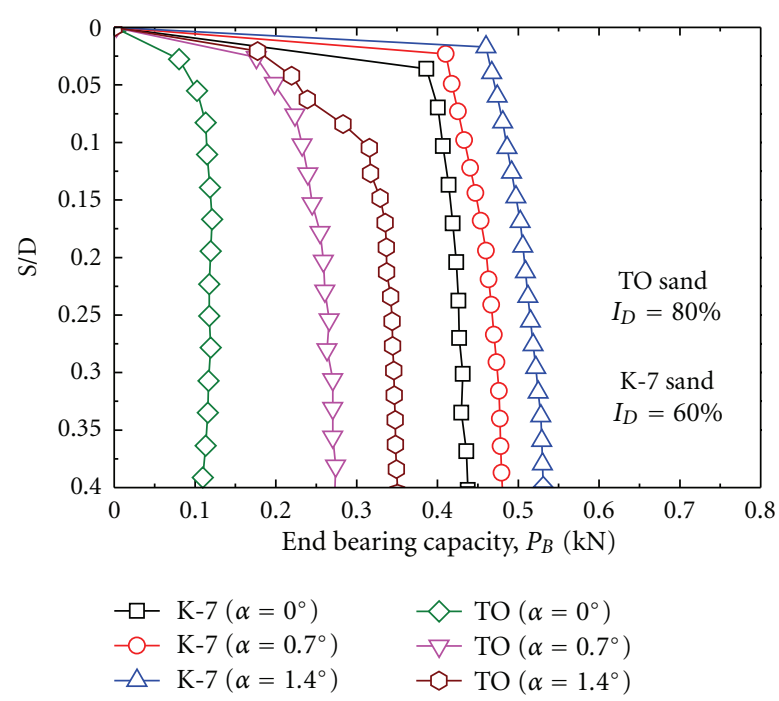

FIGURE 2: End-bearing resistance of K-7 and TO sands.

develop an analytical model for evaluating the end-bearing capacity, and it is imperative to check the validity and liability of verifying with prototypes and real pile references, which will be discussed in the next section.

\section{Analytical Model to Evaluate End-Bearing Capacity}

The compressibility of soil, shear stiffness, and strength all affect the pile end-bearing capacity in sands. Compressibility is believed to differ greatly, ranging from incompressible silica sands to highly compressible carbonate sands for different types of soils. A spherical cavity expansion solution 
TABLE 1: Geometrical configuration of different types of piles.

\begin{tabular}{|c|c|c|c|c|c|c|c|}
\hline Types of model piles & Naming & $\begin{array}{c}L \\
\mathrm{~mm}\end{array}$ & $\begin{array}{c}D_{t} \\
\mathrm{~mm}\end{array}$ & $\begin{array}{c}D \\
\mathrm{~mm}\end{array}$ & $\alpha$ & FRP reinforcement direction & Modulus of elasticity (GPa) \\
\hline \multirow{3}{*}{ Model steel piles } & $S$ & 500 & 25 & 25 & 0.00 & na & 2 \\
\hline & $\mathrm{T}-1$ & 500 & 35 & 25 & 0.70 & na & 2 \\
\hline & $\mathrm{T}-2$ & 500 & 45 & 25 & 1.40 & na & 2 \\
\hline \multirow{4}{*}{ Prototype FRP piles } & FC & 1524 & 168.3 & 168.3 & 0.00 & na & 31.86 \\
\hline & T-3 & 1524 & 170.0 & 198.0 & 0.53 & $0^{\circ}$ & 33.20 \\
\hline & $\mathrm{T}-4$ & 1524 & 159.0 & 197.0 & 0.71 & $0^{\circ}$ & 33.15 \\
\hline & $\mathrm{T}-5$ & 1524 & 155.0 & 215.0 & 1.13 & $0^{\circ}$ & 33.15 \\
\hline
\end{tabular}

Note: $L$ : length of pile; $D_{t}$ : diameter at the pile head; $D$ : pile tip diameter; FRP: fiber-reinforced polymer; $\alpha$ : angle of tapering; na: not applicable.

TABLE 2: Geotechnical properties of different sands.

\begin{tabular}{|c|c|c|c|}
\hline Descriptions & TO & $\mathrm{K}-7$ & Fanshawe brick sand (Sakr et al.) [23-25] \\
\hline Density of particles, $\left(\mathrm{g} / \mathrm{cm}^{3}\right) \rho_{s}$ & 2.65 & 2.62 & 2.68 \\
\hline Maximum density, $\left(\mathrm{g} / \mathrm{cm}^{3}\right) \rho_{\max }$ & 1.64 & 1.60 & 1.772 \\
\hline Minimum density, $\left(\mathrm{g} / \mathrm{cm}^{3}\right) \rho_{\min }$ & 1.34 & 1.19 & 1.466 \\
\hline Density at $I_{D} 80 \%,\left(\mathrm{~g} / \mathrm{cm}^{3}\right) \rho_{80}$ & 1.58 & 1.52 & na \\
\hline Density at $I_{D} 60 \%,\left(\mathrm{~g} / \mathrm{cm}^{3}\right) \rho_{60}$ & 1.52 & 1.43 & na \\
\hline Maximum void ratio, $e_{\max }$ & 0.98 & 1.20 & 0.794 \\
\hline Minimum void ratio, $e_{\min }$ & 0.62 & 0.64 & 0.484 \\
\hline Void ratio at $I_{D} 90 \%, e_{90}$ & na & na & 0.68 \\
\hline Void ratio at $I_{D} 80 \%, e_{80}$ & 0.68 & 0.73 & na \\
\hline Void ratio at $I_{D} 60 \%, e_{60}$ & 0.74 & 0.83 & na \\
\hline Effective grain size, $(\mathrm{mm}) D_{10}$ & na & na & 0.14 \\
\hline Mean grain size, $(\mathrm{mm}) D_{50}$ & na & na & 0.26 \\
\hline Uniformity coefficient, $U_{c}$ & 1.40 & 4.0 & 2.143 \\
\hline Coefficient of curvature, $U_{c}^{\prime}$ & 0.86 & 1.21 & 0.905 \\
\hline Percent fines, $(\%) F_{c}$ & 1.10 & 14 & na \\
\hline Peak stress, $(\mathrm{deg})^{\circ} \phi$ & 42.00 & 47.00 & 37.00 \\
\hline Critical stress state, $(\mathrm{deg})^{\circ} \phi_{\mathrm{cv}}^{\prime}$ & 32.00 & 34.00 & 31.00 (assumed) \\
\hline
\end{tabular}

has been incorporated to estimate the end-bearing capacity of cylindrical straight piles in closed forms by Yasufuku et al. $[7,8]$. On the basis of this estimation technique, this model is advanced by introducing the angle of tapering to evaluate the end-bearing capacity of tapered piles. Figures 4(a) and 4(b) explain a modified failure mechanism using a spherical cavity expansion theory which was initially postulated by Yasufuku et al. [7, 8] for frictional soils with cavity expansion pressure $p_{u}$ proposed by Vesic [4] to determine the ultimate bearing capacity $q_{p c a l}$. In the modified mechanism of tapered piles, it is assumed that a rigid cone of soil exists beneath the pile tip with the angle $\Psi^{\prime}\left(=\pi / 4+\phi^{\prime} / 2+\alpha\right)$ and that outside the conical region, the zone is subjected to isotropic stress which is equal to the cavity expansion pressure $p_{u}$. In addition, the active earth pressure conditions $\sigma_{A}\left[=q_{\text {pcal }}\{(1-\right.$ $\left.\left.\sin \left(\phi_{\mathrm{cv}}^{\prime}+2 \alpha\right)\right) /\left(1+\sin \left(\phi_{\mathrm{cv}}^{\prime}+2 \alpha\right)\right\}\right]$ are considered to exist immediately beneath the pile tip along AC plane. Then, at point $\mathrm{B}$, the moment is created as shown by Figure 4 for the cavity expansion pressure $p_{u}$, ultimate end-bearing pressure $q_{p \text { cal }}$, and the active earth pressure $\sigma_{A}[3]$. Then, the ultimate bearing capacity $q_{\text {pcal }}$ of the tapered pile can be addressed with the formula

$$
q_{p \mathrm{cal}}=\frac{1}{1-\sin \left(\phi_{\mathrm{cv}}^{\prime}+2 \alpha\right)} p_{u}
$$

The cavity expansion pressure $p_{u}$ on the basis of Vesic theory [4] can be written as

$$
p_{u}=F_{q} \frac{\left(1+2 K_{0}\right)}{3} \sigma_{v}^{\prime}
$$

where

$$
\begin{aligned}
& F_{q}=\frac{3\left(1+\sin \phi_{\mathrm{cv}}^{\prime}\right)}{\left(3-\sin \phi_{\mathrm{cv}}^{\prime}\right)}\left[I_{r r}\right]^{\left(4 \sin \phi_{\mathrm{cv}}^{\prime}\right) / 3\left(1+\sin \phi_{\mathrm{cv}}^{\prime}\right)}, \\
& I_{r r}=\frac{I_{r}}{1+I_{r} \Delta_{\mathrm{av}}}, \quad I_{r}=\frac{3 G}{\left(1+2 K_{0}\right) \sigma_{v}^{\prime} \tan \phi_{\mathrm{cv}}^{\prime}},
\end{aligned}
$$

where $F_{q}, I_{r r}$, and $I_{r}$ are known as dimensionless spherical cavity expansion factors, reduced rigidity index, and rigidity 


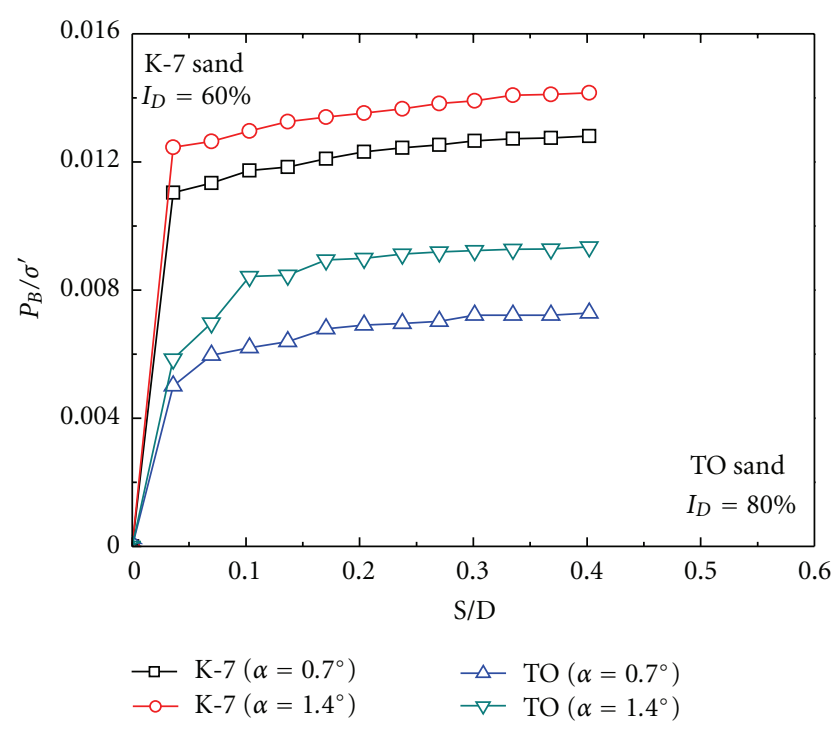

Figure 3: Normalized total end-bearing capacities of K-7 and TO sands.

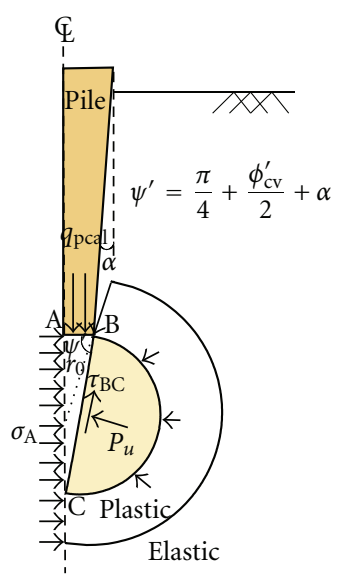

(a)

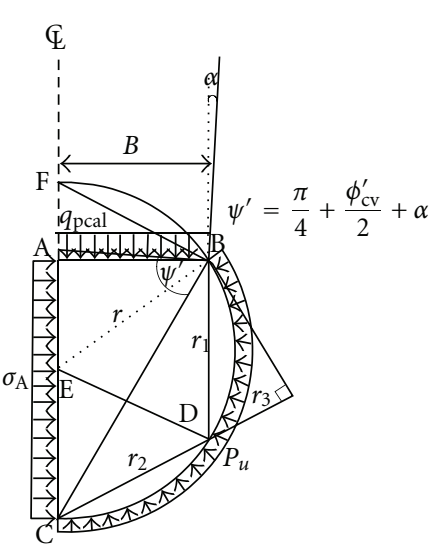

(b)
FIGURE 4: (a) Concept of modified failure mechanism around the tapered pile tip in cavity expansion solution and (b) geometry of calculation procedure to find ultimate end-bearing capacity of tapered pile.

index, respectively, which are associated with friction angle $\phi^{\prime}$, shear stiffness $G$, and average volumetric strain $\Delta_{\mathrm{av}}$ for the plastic zone around a cavity, with the coefficient of earth pressure at rest $K_{0}$ and overburden pressure $\sigma_{v}^{\prime}$. $I_{r}$ provides a ratio of shear stiffness to strength, and $I_{r r}$ is a parameter in lieu of the soil compressibility, in which shear stiffness, shear strength, and average volumetric strain are combined. Proceeding, $\sigma_{v}^{\prime}$ is basically calculated as an averaged unit weight $\gamma_{\mathrm{av}}\left(=\gamma_{\mathrm{av}} z\right)$. On the basis of the theoretical relation to plastic equilibrium, Ochiai [11] derived the critical state friction angle $\phi_{\mathrm{cv}}^{\prime}$ as

$$
K_{0}=1-\sin \phi_{\mathrm{cr}}^{\prime} .
$$

Asserting $\phi_{\mathrm{cv}}^{\prime}$ is effective and rational in practical applications as a strength parameter [12-15], the friction angle guarantees the minimum shear strength under the same initial conditions and soil density, with initial fabric and confining pressure considered to be independent. The value of $\phi_{\mathrm{cv}}^{\prime}$ of sands is almost equal to the maximum friction angle under the high confining stress, which will be mobilized below the pile tip $[16,17]$. Therefore, the $\phi_{c v}^{\prime}$ is recommended for estimating the pile end-bearing capacity of sands. At the same time, an empirical equation $G=7.0 N^{0.72}$ is used to predict the $G$-value in the strain level of $10^{-3}$ from the measured $N$-value [18], in MPa. The penetration resistance is presumed to increase with the square of the relative density and to be directly proportional to the effective overburden pressure and inversely proportional to the void ratios [19] such that

$$
N=\frac{9 I_{D}^{2}}{\left(e_{\max }-e_{\min }\right)^{1.7}}\left\{\frac{\sigma_{v}^{\prime}}{98}\right\}^{0.5}
$$

where $I_{D}$ is relative density and $e_{\max }$ and $e_{\min }$ are maximum and minimum void ratios. Rearranging values of $N$ from (5), the empirical correlation can be expressed as

$$
G=7.0\left\{\frac{9 I_{D}^{2}}{\left(e_{\max }-e_{\min }\right)^{1.7}}\left\{\frac{\sigma_{v}^{\prime}}{98}\right\}^{0.5}\right\}^{0.72} .
$$

The empirical equation $\Delta_{\mathrm{av}}=50\left(I_{r}\right)^{-1.8}$ is a function of $I_{r}$ in a simple manner [6]. Rearranging from (3), a function of $G, K_{0}, \sigma_{v}^{\prime}$, and $\phi_{\mathrm{cv}}^{\prime}$ can be written in this form

$$
\Delta_{\mathrm{av}}=50\left\{\frac{\left(\left(1+2 K_{0}\right) / 3\right) \sigma_{v}^{\prime} \tan \phi_{\mathrm{cv}}^{\prime}}{G}\right\}^{1.8} .
$$

Equation (7) measures the average volumetric stain $\Delta_{\mathrm{av}}$ for a plastic zone around a cavity, which increases with increasing overburden pressure in the ground. The rearrangement of this equation addresses the evaluation of the ultimate pile end-bearing capacity as follows:

$$
q_{p c a l}=\frac{A^{\prime}}{1-\sin \left(\phi_{\mathrm{cv}}^{\prime}+2 \alpha\right)}\left\{\frac{G / \sigma_{v}^{\prime}}{B^{\prime}+D^{\prime}\left(G /\left(\sigma_{v}^{\prime}\right)\right)^{-0.8}}\right\}^{C^{\prime}} \sigma_{v}^{\prime},
$$

where

$$
\begin{gathered}
A^{\prime}=\frac{3\left(1+\sin \phi_{\mathrm{cv}}^{\prime}\right)}{\left(3-\sin \phi_{\mathrm{cv}}^{\prime}\right)}\left(\frac{1+2 K_{0}}{3}\right), \quad B^{\prime}=\left(\frac{1+2 K_{0}}{3}\right) \tan \phi_{\mathrm{cv}}^{\prime}, \\
C^{\prime}=\frac{4 \sin \phi_{\mathrm{cv}}^{\prime}}{3\left(1+\sin \phi_{\mathrm{cv}}^{\prime}\right)}, \quad D^{\prime}=50\left\{\left(\frac{1+2 K_{0}}{3}\right) \tan \phi_{\mathrm{cv}}^{\prime}\right\}^{1.8} .
\end{gathered}
$$

The Kondner types of hyperbolic curves are useful for predicting the load settlement curves of nondisplacement piles in virgin loading [20-22]. A simple hyperbolic function is assumed for estimating the relationship between the applied pile tip stress, $q_{\mathrm{cal}}$, and the corresponding normalized pile tip settlement, $S / D$, as

$$
q_{\mathrm{cal}}=\frac{S / D}{n+m(S / D)},
$$


where $n$ and $m$ are experimental parameters corresponding to the inverse values of suitable initial shear stiffness and ultimate pile stress, respectively.

When introducing reference displacement $(S / D)_{\mathrm{ref}}=$ 0.25 , presented by Hirayama [22], which is empirically derived for nondisplacement piles in sands, expressed as the normalized settlement $S / D$ required to mobilize the half of the ultimate end-bearing capacity $q_{p \text { cal }}$, the inverse of the initial shear stiffness is expressed such that

$$
q_{\mathrm{cal}}=\frac{S / D}{\{0.25+S / D\}} q_{p \mathrm{cal}}
$$

\section{Validity of the Model}

The validity of the model was checked after verifying it with a small model and prototype pile materials, including with different sources of data. The parameters of TO sand K-7 sand and pile materials have been taken from Manandhar et al. [1] and Fanshawe brick sand from Sakr et al. [23-25]. This research employs a cylindrical fiber-reinforced polymer (FRP) FC pile and a three-tapered FRP composite tapered pile, which is an off-the-shelf pipe with an average diameter of $162.4 \mathrm{~mm}$ and a ply angle of $55^{\circ}$. These fabricated FRP tapered piles using six layers of glass filament wound (GFW) were placed at ply angles $0^{\circ}$ (parallel to pile axis) and $90^{\circ}$ (hoop layer) [23] (Table 1). The pile installation of Fanshawe brick sand is confined to a low pressure (LP) with an initial radial stress of $30 \mathrm{kPa}$ and a vertical pressure of $60 \mathrm{kPa}$, as well as a high pressure (HP) with an initial radial stress of $60 \mathrm{kPa}$ and a vertical pressure of $120 \mathrm{kPa}$ at different depths and mobilized up to 0.4 normalized settlement ratios. The fundamental geotechnical properties of sand are set out in Table 2. The vertical pressure can be obtained by using the simple formula discussed in the previous section. Figure 5 shows there is increase in total end-bearing capacity when increasing the tapering angles in the closed form cavity expansion solution. Larger total end-bearing resistance is reflected by high density ground. Similarly, high end-bearing capacity has been obtained at a high radial stress at the same density ground, as shown by Figure 6 .

Further, the total end-bearing capacity measured in $\mathrm{kN}$ is

$$
P_{B}=q_{\mathrm{cal}} \pi r_{b}^{2}
$$

where $r_{b}$ is the radius of the pile tip at the middle point of the embedded pile section.

The following arrangement can be obtained by substituting the value of $q_{\mathrm{cal}}$ using (1), (2), (10), and (11) into (10):

$$
\begin{aligned}
P_{B}= & \frac{S / D}{\{0.25+S / D\}} \frac{1}{1-\sin \left(\phi_{\mathrm{cv}}^{\prime}+2 \alpha\right)} \\
& \times A^{\prime}\left\{\frac{G / \sigma_{v}^{\prime}}{B^{\prime}+D^{\prime}\left(G / \sigma_{v}^{\prime}\right)^{-0.8}}\right\}^{C^{\prime}} \sigma_{v}^{\prime} \pi r_{b}^{2}
\end{aligned}
$$

Assume $\left(P_{B}\right)_{\alpha=0}$ for the total end-bearing capacity of straight piles. When the total end-bearing capacity of tapered piles is normalized with the total end-bearing capacity of

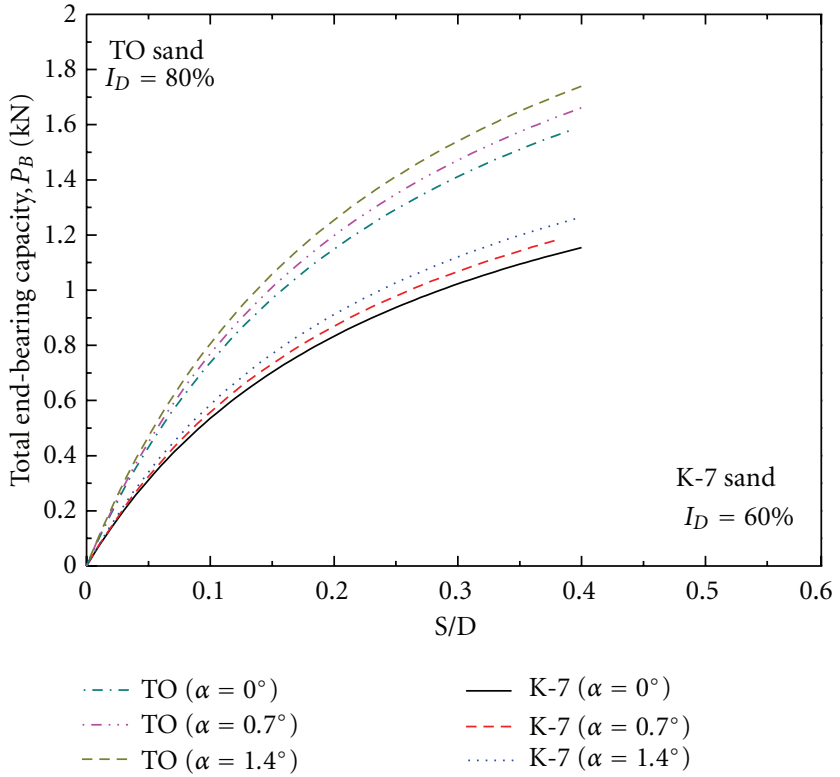

FIGURE 5: Total end-bearing capacity of TO and K-7 sands of different piles at normalized settlement ratio.

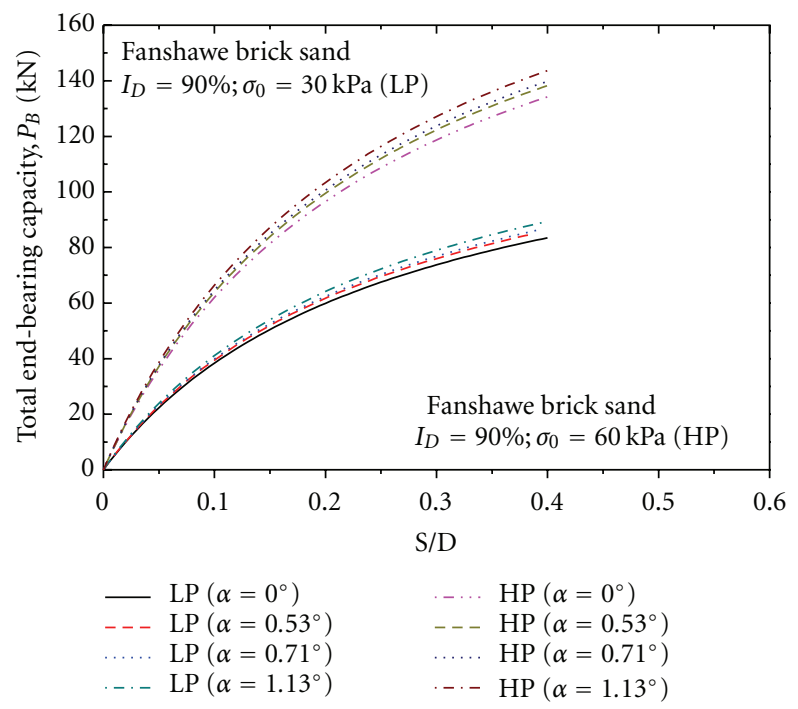

Figure 6: Total end-bearing capacity of Fanshawe brick sand of different piles at normalized settlement ratio.

straight piles by taking ratios between them, the following relation is obtained:

$$
\frac{P_{B}}{\left(P_{B}\right)_{\alpha=0}}=\frac{1 /\left(1-\sin \left(\phi_{\mathrm{cV}}^{\prime}+2 \alpha\right)\right)}{1 /\left(1-\sin \phi_{\mathrm{cV}}^{\prime}\right)} .
$$

This equation shows the relationship between the angle of internal friction at a critical state and tapering angle as the interdependent function for evaluating the total endbearing capacity of tapered piles. This verifies that the endbearing capacity depends on the angle of internal friction at the critical state condition and the tapering angle of piles only. When there is a change in the angle of tapering, 
TABLE 3: Pile geometry and soil characteristics from different source papers.

\begin{tabular}{|c|c|c|c|c|c|c|c|}
\hline \multirow{2}{*}{ Source paper } & \multirow{2}{*}{ No. } & \multicolumn{2}{|c|}{ Pile geometry } & \multicolumn{4}{|c|}{ Soil characteristics } \\
\hline & & Diameter, $d(\mathrm{~m})$ & Length, $L(\mathrm{~m})$ & Soil type & $\sigma_{v}^{\prime}(\mathrm{kPa})$ & $\phi_{\mathrm{cv}, \mathrm{av}}^{\prime}\left({ }^{\circ}\right)$ & $N_{\mathrm{av}}(\mathrm{G})(\mathrm{MPa})$ \\
\hline BCP (1B) (1971) [27] & 1 & 0.2 & 4 & Fine sand & 60 & $35(34-36)$ & $20(60.5)$ \\
\hline BCP (5C) (1971) [27] & 2 & 0.2 & 11 & Dense sand & 170 & $37(36-38)$ & $48(133.5)$ \\
\hline \multirow{4}{*}{ JGS data (1993) [28] } & 3 & 1.5 & 44.5 & Sand & 300 & 35 & $25(71.1)$ \\
\hline & 4 & 1.5 & 32 & Sand & 356 & $(34-36)$ & $30(81)$ \\
\hline & 5 & 1.5 & 26.5 & Sand & 256 & 35 & $30(81)$ \\
\hline & 6 & 1.5 & 22.4 & Sand & 212 & $(34-36)$ & $30(81)$ \\
\hline \multirow{3}{*}{ Yasufuku et al. (2001) [8] } & 7 & & & & 100 & & $-(21.9)$ \\
\hline & 8 & 0.03 & - & Quiou sand & 200 & 36 & $-(42)$ \\
\hline & 9 & & & & 400 & & $-(47.0)$ \\
\hline
\end{tabular}

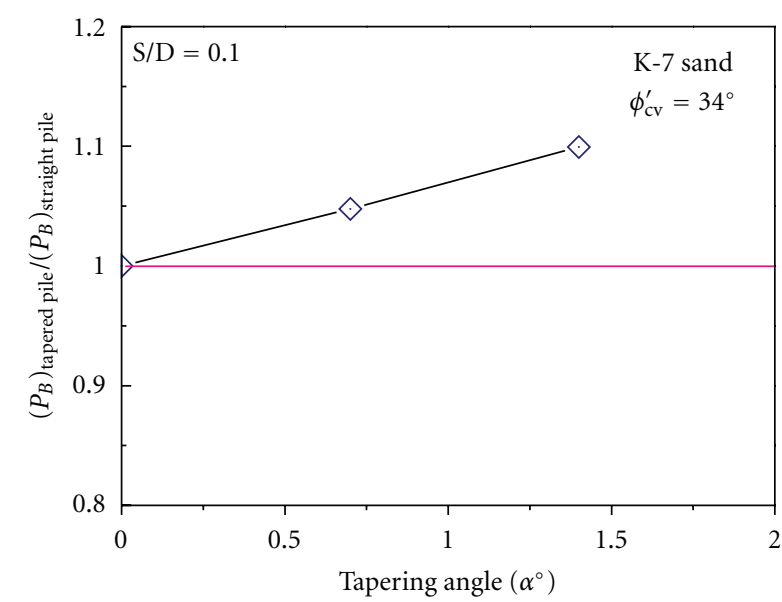

FIGURE 7: Normalized end-bearing capacity of K-7 sand at different pile tapering angles.

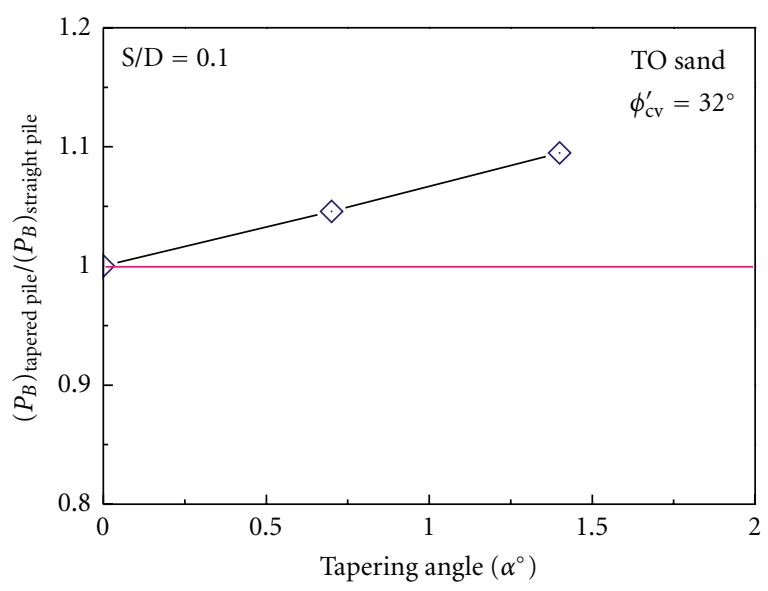

FIGURE 8: Normalized end-bearing capacity of TO sand at different pile tapering angles.

the end-bearing capacity will also change independently of overburden pressure, confining pressure, and the shear modulus of soil. Hence, Figures 7, 8, and 9 were plotted to verify this mechanism of normalized ratios of total endbearing capacity for different sands. There is a clear increase

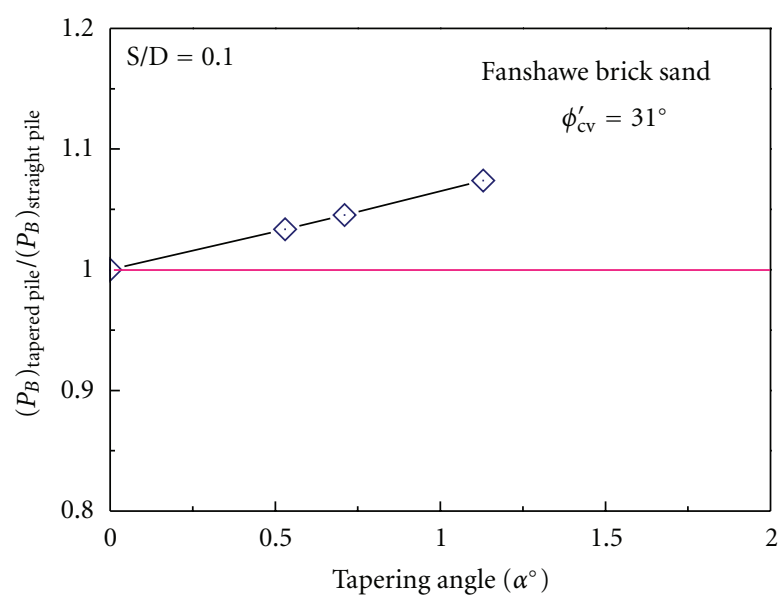

FIGURE 9: Normalized end-bearing capacity of Fanshawe brick sand and different pile tapering angles.

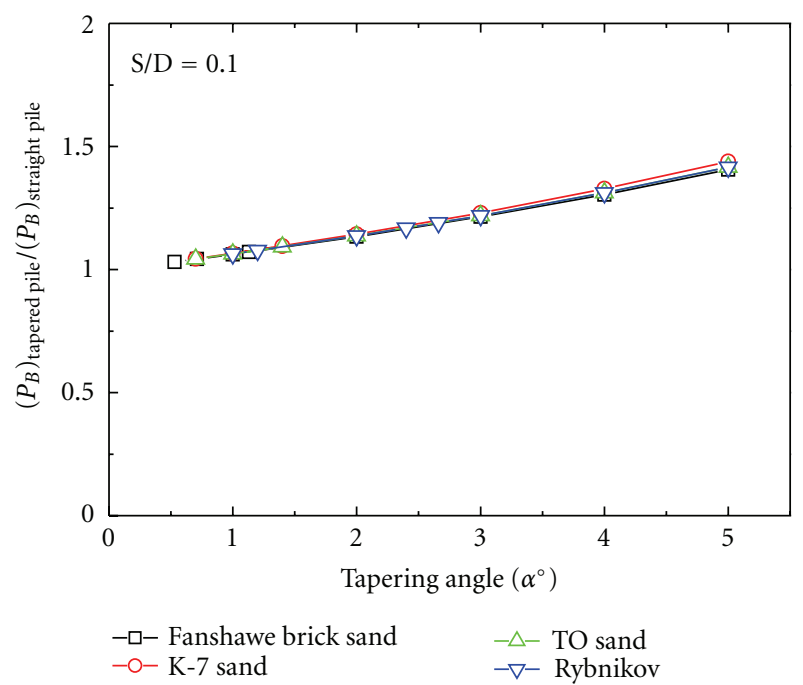

FIGURE 10: Effect of tapering angle on normalized end-bearing capacity at 0.1 settlement ratio.

in the total end-bearing capacity at 0.1 settlement ratios for all types of soils and pile materials.

Further, different tapering angles were asserted to understand the behavior of end-bearing capacity in sands. 


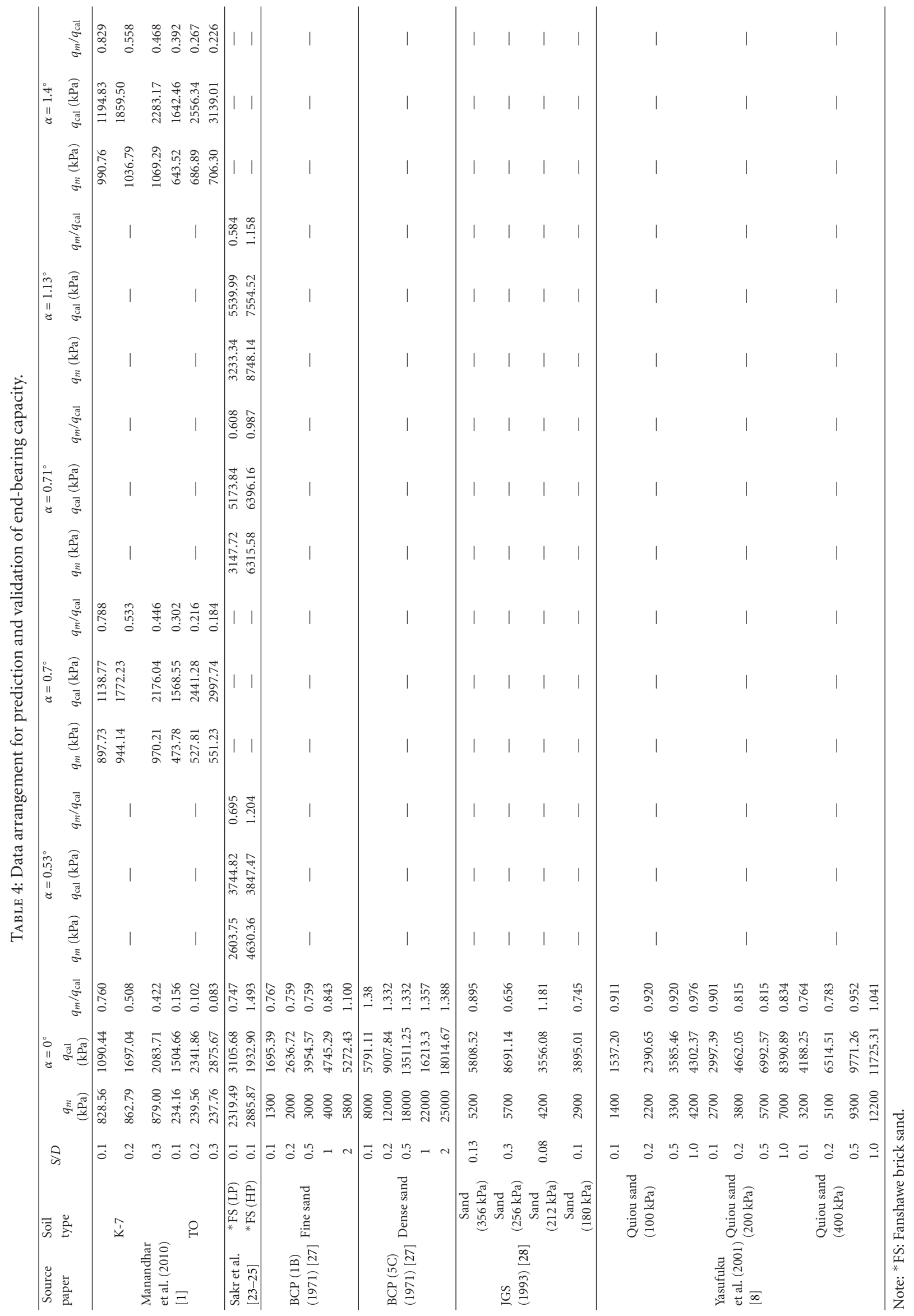




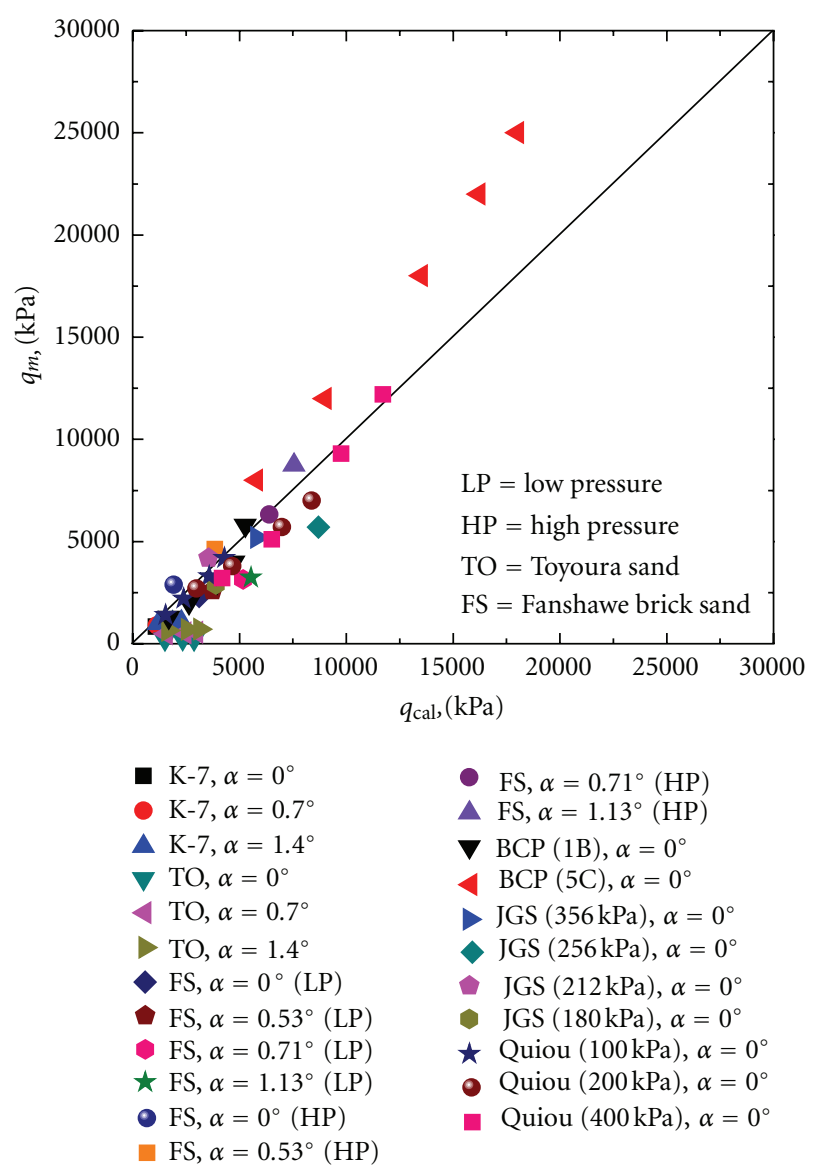

FIGURE 11: Calculated and measured end-bearing capacity of different types of piles.

This study employed model tests, the prototype test described by Sakr et al. [23-25] and the real type Rybnikov [26] pile. Rybnikov carried out tests in the Irtysh Pavlodar region of the former Soviet Union and used bored castin-place tapered piles. The holes for the piles were drilled with endless screws. Seven different piles were consummated having lengths of $4.5 \mathrm{~m}$ each, constituting five tapered piles and two cylindrical piles to comprehend the behavior of tapered piles with respect to straight piles. In this study, only the geometry of pile materials is considered for the analyses, with the assumption of soil properties obtained by TO sand as shown by Table 2 .

Figure 10 represents the effects of the tapering angle in four different types of pile materials and soils by dividing the total end-bearing capacity of straight piles to tapered piles. The results show an increase in the end-bearing capacity of almost $10 \%$ for the maximum tapered angle, indicating that the end-bearing capacity is affected by the angle of tapering and angle of internal friction only.

Afterwards, the measured and calculated results of the end bearing capacity were plotted to verify the model. The model was verified with the addition of various reference data. The measured and predicted data for the end-bearing capacity, measured in $\mathrm{kPa}$, are shown in Tables 3 and 4, respectively. Figure 11 shows how the proposed model fits remarkably well and that it is valid for evaluating endbearing capacity when various data have been obtained. The measured and calculated results were plotted in a $1: 1$ ratio and proved the validity of the model with the parameters used with different types of pile geometry and sands.

\section{Conclusions}

The benefits of tapered piles obtained through evidence from small model tests in the laboratory lead to the development of an analytical model for the estimation of the end-bearing capacity of tapered piles. The assertion of tapering angle in the analytical spherical cavity expansion theory was successfully evaluated for the end-bearing capacity of tapered piles. The proposed models have been validated through the verification of model tests, prototype tests and real type pile tests. The main conclusions drawn using the various proposed models are summarized as follows.

(1) Parametric studies with the key variable of the tapering angle show that the proposed model effectively sustains the general behavior of tapered piles in evaluating the end-bearing.

(2) The total end-bearing capacity of tapered piles confines to restrain the failure mode, which increases the end-bearing capacity, and the model is supported by the measured data.

\section{Acknowledgments}

The authors would like to extend their gratitude to Professor Kiyoshi Omine for his invaluable advice. In addition, heartfelt thanks go to laboratory assistant Mr. Michio Nakashima and colleague Mr. Tohio Ishimoto for their continued support.

\section{References}

[1] S. Manandhar, N. Yasufuku, K. Omine, and T. Kobayashi, "Response of tapered piles in cohesionless soil based on model tests," Journal of Nepal Geological Society, vol. 40, pp. 85-92, 2010.

[2] S. Manandhar, Bearing capacity of tapered piles in sands [Ph.D. thesis], Kyushu University, 2010.

[3] S. Manandhar and N. Yasufuku, "End bearing capacity of tapered piles in sands using cavity expansion theory," Memoirs of the Faculty of Engineering, Kyushu University, vol. 71, no. 4, pp. 77-99, 2011.

[4] A. S Vesic, "Expansion of cavities in infinite soil mass," Journal of Soil Mechanics and Foundation Engineering, vol. 98, no. 3, pp. 265-290, 1972.

[5] M. M. Baligh, "Cavity expansion in sands with curved envelopes," Journal of Geotechnical Engineering Division, vol. 102, no. GT11, pp. 1131-1145, 1976.

[6] J. M. O. Hughes, C. P. Wroth, and D. Windle, "Pressuremeter tests in sands," Geotechnique, vol. 27, no. 4, pp. 455-477, 1977.

[7] N. Yasufuku and A. F. L. Hyde, "Pile end-bearing capacity in crushable sands," Geotechnique, vol. 45, no. 4, pp. 663-676, 1995. 
[8] N. Yasufuku, H. Ochiai, and S. Ohno, "Pile end-bearing capacity of sand related to soil compressibility," Soils and Foundations, vol. 41, no. 4, pp. 59-71, 2001.

[9] Japanese Industrial System A 1224, Japanese Geotechnical Engineering Society, 0161, "The methods and description of soil tests," First revised version, pp. 59-64.

[10] S. Miura and S. Toki, "A sample preparation method and its effect on static and cyclic deformation-strength properties of sand," Soils and Foundations, vol. 22, no. 1, pp. 61-77, 1982.

[11] H. Ochiai, "The coefficient of earth pressure at rest of sands," Domestic Edition of Soils and Foundations, vol. 16, no. 2, pp. 105-111, 1976 (Japanese).

[12] N. Yasufuku, H. Ochiai, and Y. Maeda, "Geotechnical analysis of skin friction of cast-in-place piles," in Proceedings of the 14th International Conference on Soil Mechanics and Foundation Engineering (SMFE '97), pp. 921-924, Hamburg, Germany, 1997.

[13] N. Yasufuku, H. Ochiai, J. M. Kwag, and K. Miyazaki, "Effectiveness of critical state friction angle of volcanic ash soils in design applications," in Proceedings of the International Symposium on Problematic Soils, vol. 1, pp. 189-193, ISTohoku, Sendai, Japan, 1998.

[14] N. Yasufuku, H. Ochiai, and Y. Maeda, "Geotechnical analysis of skin friction of cast-in-place piles related to critical state friction angle," Journal of Geotechnical Engineering, vol. 617/III-46, pp. 89-100, 1999 (Japanese).

[15] M. D. Bolton, "What are partial factor for?" in Proceedings of the International on Limit State Design in Geotecnical Engigeering, vol. 10, pp. 565-583, Danish Geotechnical society for ISSMFE TC23, in DGF Bulletin, Copenhagen, Denmark, 1993.

[16] N. Miura and Yamanouchi, "Effect of particle-crushing on the shear characteristics of sand," Proceedings of JSCE, vol. 260, pp. 109-118, 1977 (Japanese).

[17] N. Miura, "Point resistance of piles in sand," in Proceedings of the 11th International Conference on Soil Mechanics, vol. 3, pp. 2448-2455, San Franscisco, Calif, USA, 1985.

[18] H. Yamaguchi, "Pile end-bearing capacity based on an elastoplastic analysis and its application," Tsuchi-to-Kiso, vol. 23, no. 7, pp. 7-11, 1975 (Japanese).

[19] M. Cubrinovski and K. Ishihara, "Empirical correlation between SPT N-value and relative density for sandy soils," Soils and Foundations, vol. 39, no. 5, pp. 61-71, 1999.

[20] H. Kishida and A. Takano, "Distribution of contact pressure under base of bored piles in sand," Transaction of Architectural Institute of Japan, Part 1, vol. 260, pp. 21-33, 1977 (Japanese).

[21] H. Kishida and A. Takano, "Distribution of contact pressure under base of bored piles in sand," Transaction of Architectural Institute of Japan, Part 2, vol. 260, pp. 21-33, 1977 (Japanese).

[22] H. Hirayama, "Load-settlement analysis for bored piles using hyperbolic transfer functions," Soils and Foundations, vol. 30, no. 1, pp. 55-64, 1990.

[23] M. Sakr, M. H. El Naggar, and M. Nehdi, "Load transfer of fibre-reinforced polymer (FRP) composite tapered piles in dense sand," Canadian Geotechnical Journal, vol. 41, no. 1, pp. 70-88, 2004.

[24] M. Sakr, M. H. El Naggar, and M. L. Nehdi, "Uplift performance of FRP tapered piles in dense sand," International Journal of Physical Modelling in Geotechnics, vol. 2, pp. 1-16, 2005.

[25] M. Sakr, M. H. El Naggar, and M. Nehdi, "Wave equation analyses of tapered FRP-concrete piles in dense sand," Soil Dynamics and Earthquake Engineering, vol. 27, no. 2, pp. 166182, 2007.
[26] A. M. Rybnikov, "Experimental investigations of bearing capacity of bored-cast-in-place tapered piles," Soil Mechanics and Foundation Engineering, vol. 27, no. 2, pp. 48-52, 1990.

[27] BCP Committee, "Field tests on piles in sand," Soils and Foundations, vol. 11, no. 2, pp. 29-50, 1971.

[28] Japan Geotechnical Society, "JGS standard for vertical load tests of piles," JGS, pp. 151-206, 1993 (Japanese). 

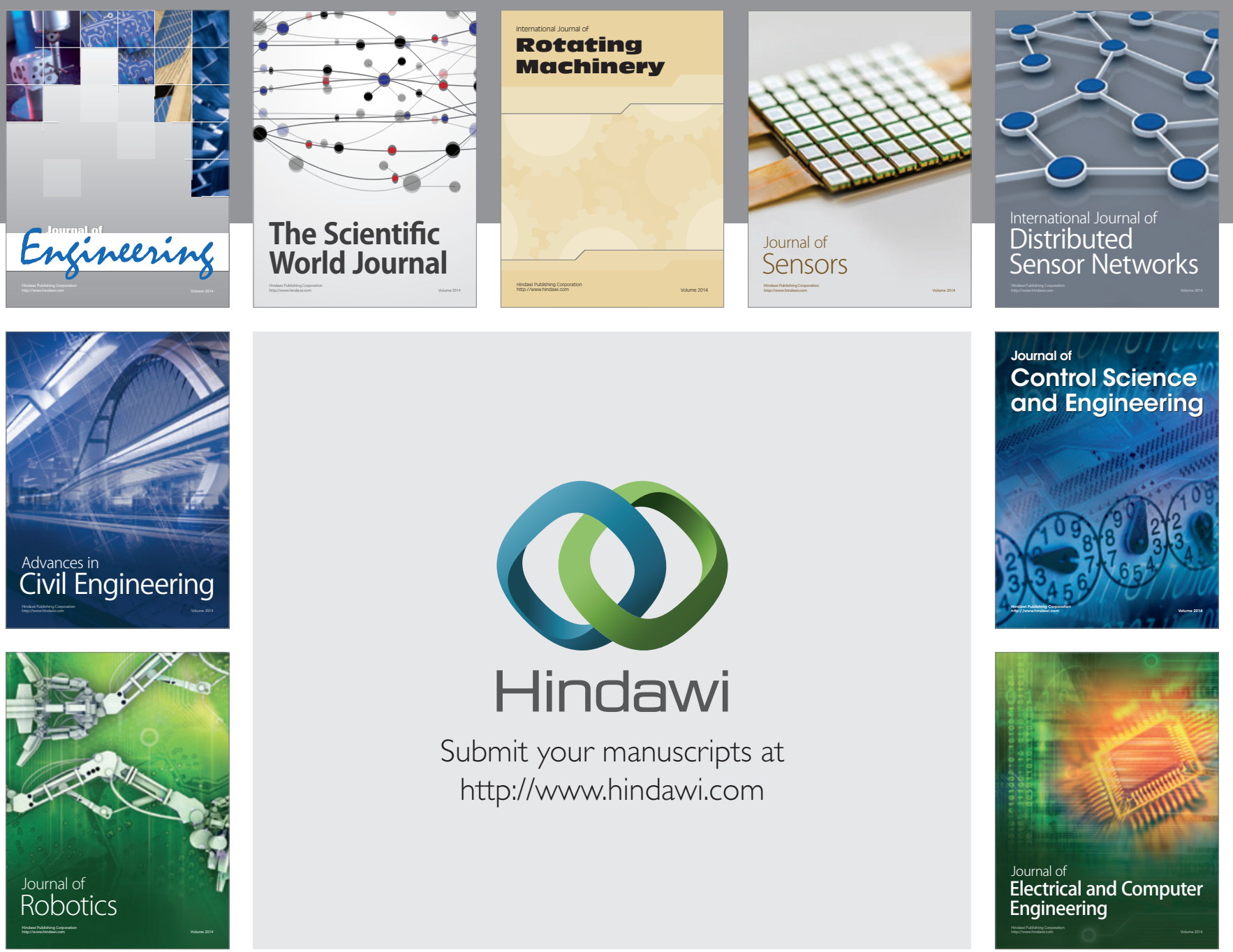

Submit your manuscripts at

http://www.hindawi.com
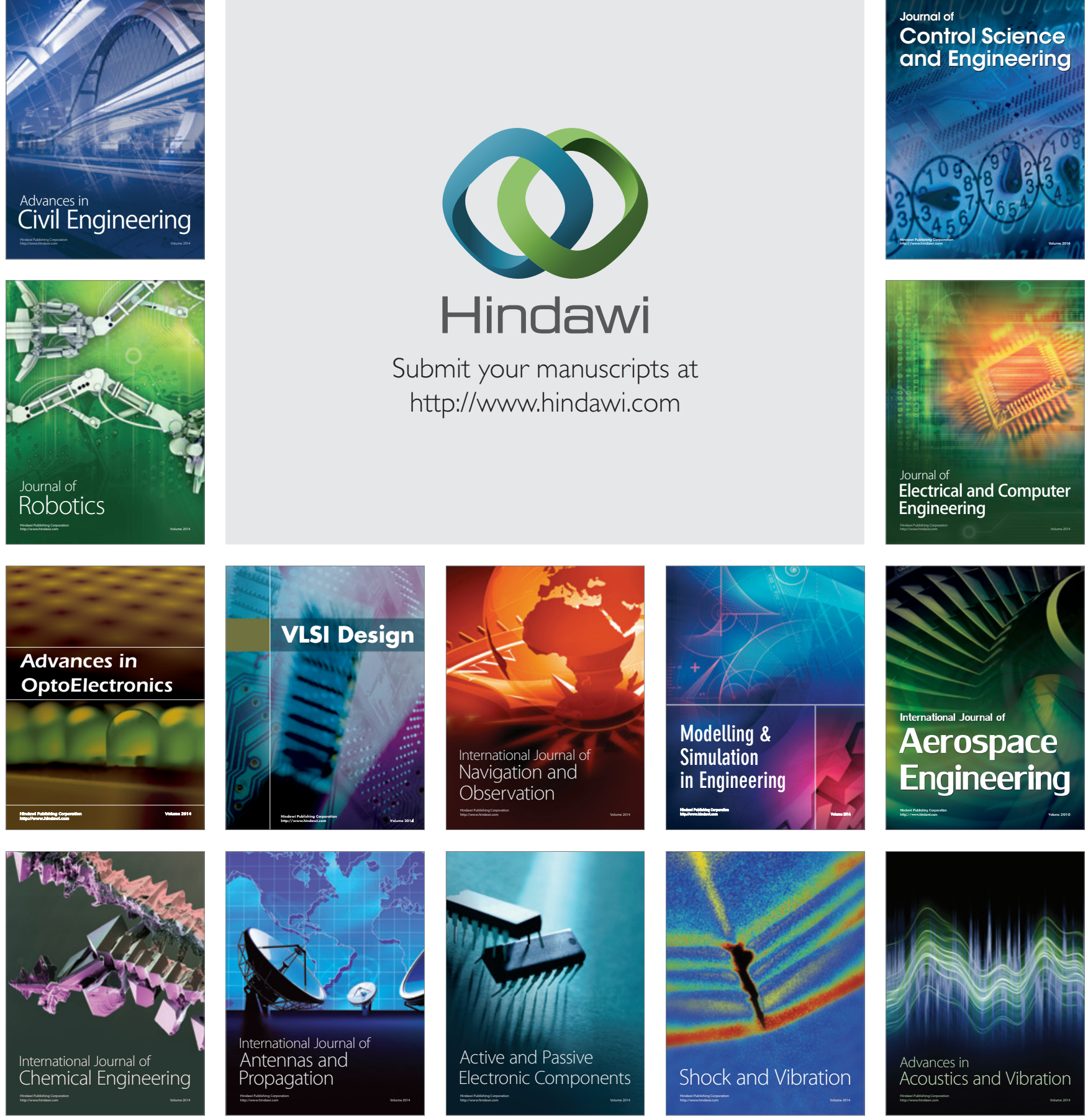